\title{
AMS President Robert Bryant: His Early Life and His Views on Mathematics
}

\author{
Allyn Jackson
}

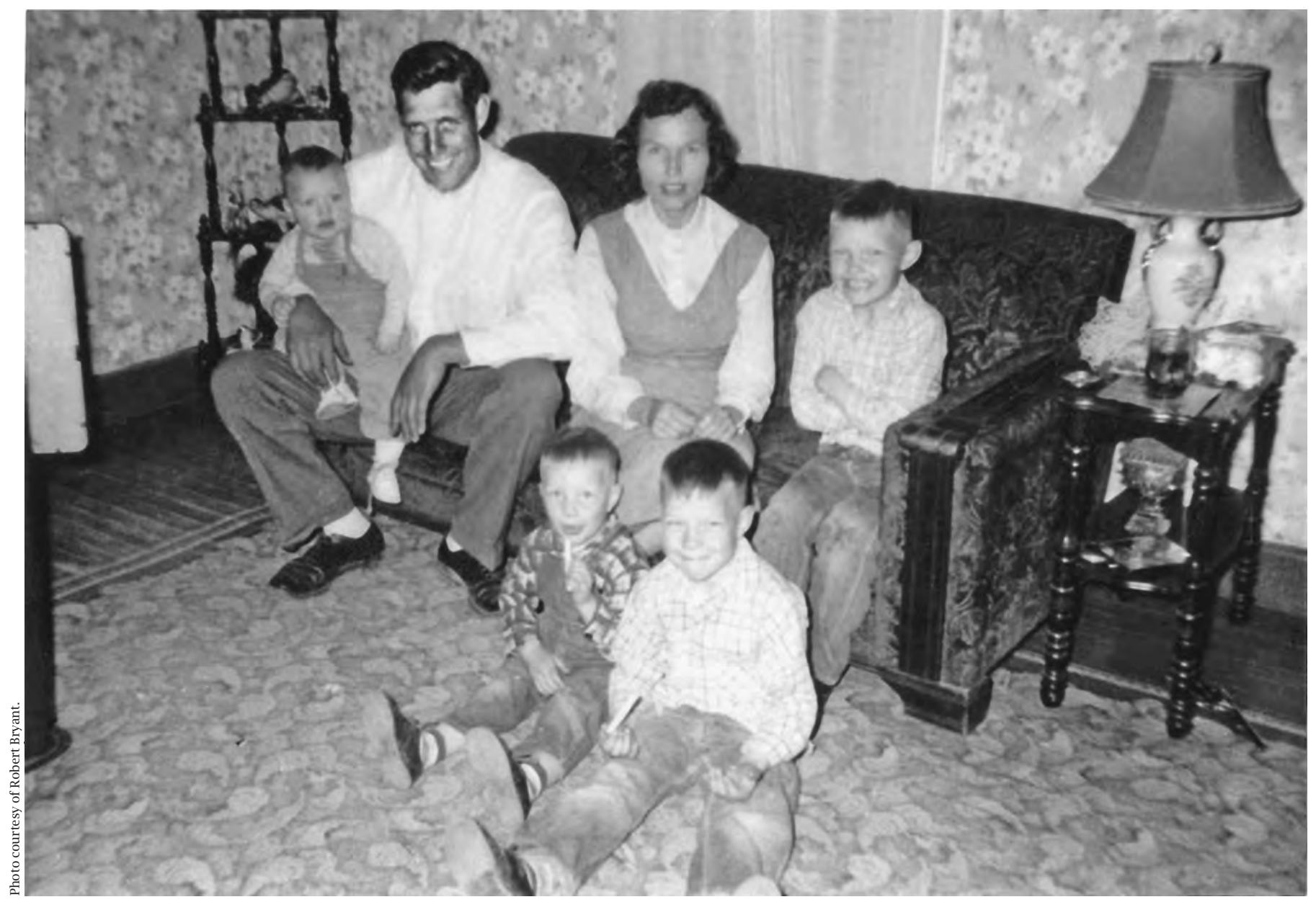

Robert Bryant admits "As a kid I hated arithmetic-it was boring and repetitive." Above, at age four, Robert sits at his mother's feet eating a peppermint stick. Also in this 1958 photo are his father and three brothers.

Allyn Jackson is senior writer and deputy editor of the Notices.

Her email address is axj@ams .org.

For permission to reprint this article, please contact:

reprint-permission@ams.org.

DOI: http://dx.doi.org/10.1090/noti1393 


\section{Pleasure in Concentrated Work}

Notices: Why do you do mathematics?

Bryant: I just enjoy understanding things. I really love a good question. In mathematics, you can sometimes have the satisfaction of being able to answer a question completely, but often just getting a better appreciation of the problem is a sufficient pleasure to motivate me to keep going. Why is it pleasurable for me and not for somebody else? I really don't know. A lot of people enjoy puzzles, and that's similar in some way. But mathematics, as well as science, requires a more sustained interest.

In math and music, "there is an intense a performance part." study part and

There is pleasure in experiencing deep concentration on something and feeling it become clearer the more you concentrate on it. There can be frustration too, but for me the pleasure outweighs anything else.

Another group of people I see who seem to have that same kind of drive, where they intensely think about something, are musicians. I think there is some similarity between the experience of working on music and doing mathematics. In both of them, there is an intense study part of it and a performance part. In mathematics, the performance part is giving a lecture in a classroom or to colleagues, where you try to convey your best understanding and communicate at the appropriate level to describe why the work is interesting and what you see in it.

People say that mathematics is logical, but the logical aspect is only part of it. Mathematicians usually don't proceed logically. They make guesses, see patterns, do experiments, develop beliefs. Almost nothing in that process is purely logical. I liked the book by Cédric Villani, Birth of a Theorem, where he describes the experience of wandering around in the dark, seeing the light, seeing things come together after a lot of effort. Why it is specifically mathematics and not something else that brings concentration like that for me is hard to say.

\section{Chemistry Fascinating, Math Even More So}

Science requires a similar kind of concentration. In high school I was always interested in science, especially chemistry. I learned a lot of mathematics as a kid, but in high school I drifted because there was no one around who knew what the next step in mathematics was. But I had a really good chemistry teacher, and I thought I'd be a chemist because I found it so fascinating.

Notices: Why didn't you?

Bryant: Well, eventually, I found mathematics more interesting, but it took a while. As a kid I hated arithmetic-it was boring and repetitive. Learning to do long division by hand with 3-digit numbers, for example-I just didn't see the point. I grew up in a small farming community in North Carolina, and I had an uncle who went to college (the first in our family), but then he dropped out and went into the navy, leaving his college textbooks at my grandmother's house. I was curious, so I looked at the books, and there was one on calculus. (There was one on organic chemistry, too, and I nearly wore that out reading it, but that's another story.) I couldn't understand it, but I liked the pictures. I could read the word problems, and there was one about the largest cylinder inscribed in a sphere. I remember thinking: "There are infinitely many cylinders you could inscribe in a sphere. How could you possibly find the biggest one?" I could not really understand the calculus book because I had not had algebra, but my uncle had also left behind a college algebra text. So I started on that; I went through it and worked all the exercises. I was in the eighth grade by then.

I was one of six kids in our family-that's not terribly big for a farming family. I went to a school with all twelve grades, so I graduated high school with essentially the same thirty-two kids I started with in the first grade. This was typical in Harnett County, North Carolina, where I grew up. At that time, the largest high school in the county had about one hundred in its graduating class. Our school was one of the smaller ones. It was a good environment in many ways, very secure and safe. All the teachers knew us, our siblings, and our families. But they weren't up on the new educational trends. There was no calculus in our high school. The math courses were Algebra I, Algebra II, Geometry, and something called Advanced Math (some probability and statistics, complex numbers, etc.); Geometry and Advanced Math were only taught in alternate years. The mathematical opportunities were few, but I worked through my uncle's calculus book and then through a book on vector calculus that was in our high school library. My teachers really didn't know what was next, so I mostly just

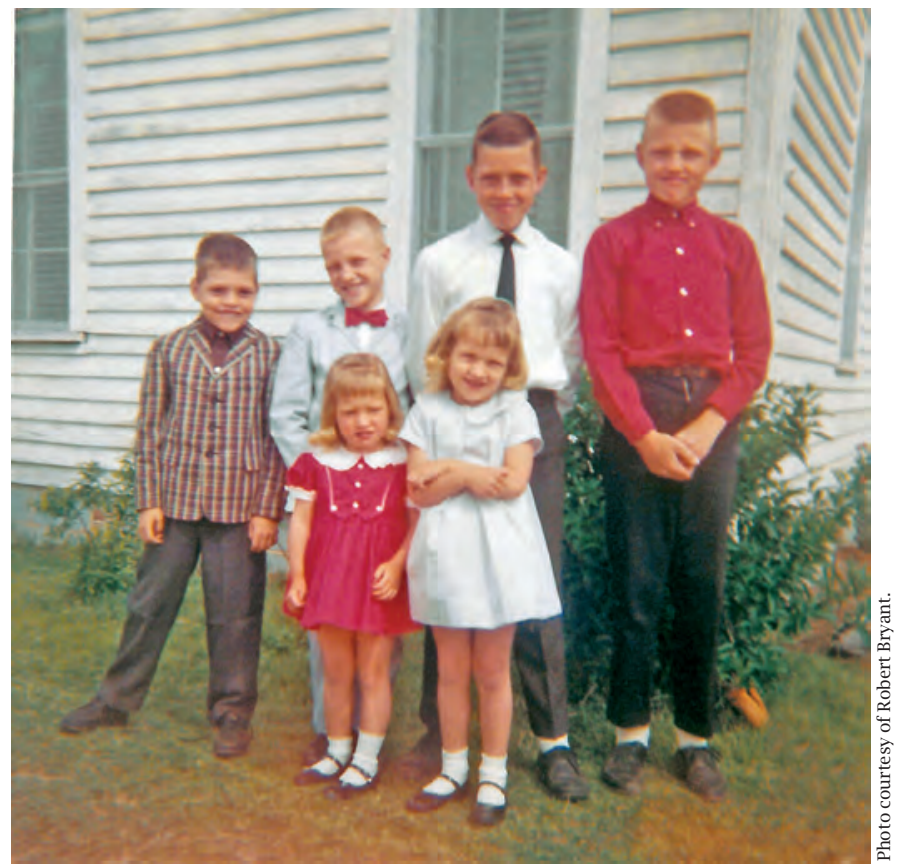

All six children in the Bryant family are dressed for church in 1964. Robert, second from the left, wears a red bow tie. 
did a lot of calculus problems in high school, and that was what I thought mathematics was.

At one point we got a new science teacher with a degree in chemistry. He was an exciting guy, and I got really interested in chemistry. I thought that was where the hot problems were. You could see chemistry doing things in the world. Right up to my senior year, I was interested in chemistry.

In my senior year I met a (now long retired) math professor from nearby Campbell College (now Campbell University). We fell to talking, and he asked, "So, you will major in mathematics, right?" I said, "No, chemistry."And he said, "Why not math?", and I said, "Well, I know all that." (I had thought I did, because I had learned calculus.) He laughed and said he would lend me some books, and that dispelled that notion pretty quickly. They were books on various things-graph theory, linear algebra, PDEs [partial differential equations], complex variables, elementary number theory, and so on. They opened my eyes to the fact that there was really a lot more interesting mathematics to learn.

In college and graduate school, I went home during the summer to farm.

\section{Life on the Farm}

Notices: What kind of farm work did you do?

Bryant: Different things, depending on the season. We grew tobacco, which was the main cash crop in our part of the state. We had the usual cows, pigs, and chickens for home consumption, and we grew a lot of our own food as well as food for the animals. Then my father realized that there was a shortage of vegetable farms and that he could fill a niche with what we called "truck crops." So, in addition to tobacco, we grew vegetables-cucumbers, squash, pepper, cabbage, etc.and we would sell them at farmers' markets. That was economically a big plus for us; we were eventually able to save enough to build a new house. (Our old house had no insulation, and we heated only two rooms in the winter.)

There was no summer vacation. When I was in college and graduate school, I went home during the summer to farm. I was an undergraduate at North Carolina State University and a graduate student at the University of North Carolina at Chapel Hill, so I was not far away. Our family needed the labor.

Notices: What was your undergraduate education like?

Bryant: I knew very little about college when I started at NC State; it was really an alien world to me. My uncle was the first in our extended family to go to college, but, as I said, he did not finish. The first to get a bachelor's degree was my older brother, who became a talented high school math teacher.

When I was at NC State, I had a great undergraduate adviser, Kwangil Koh, originally from Korea. He took me under his wing and understood that I needed a lot of guidance, even though I seemed to know a lot of mathematics

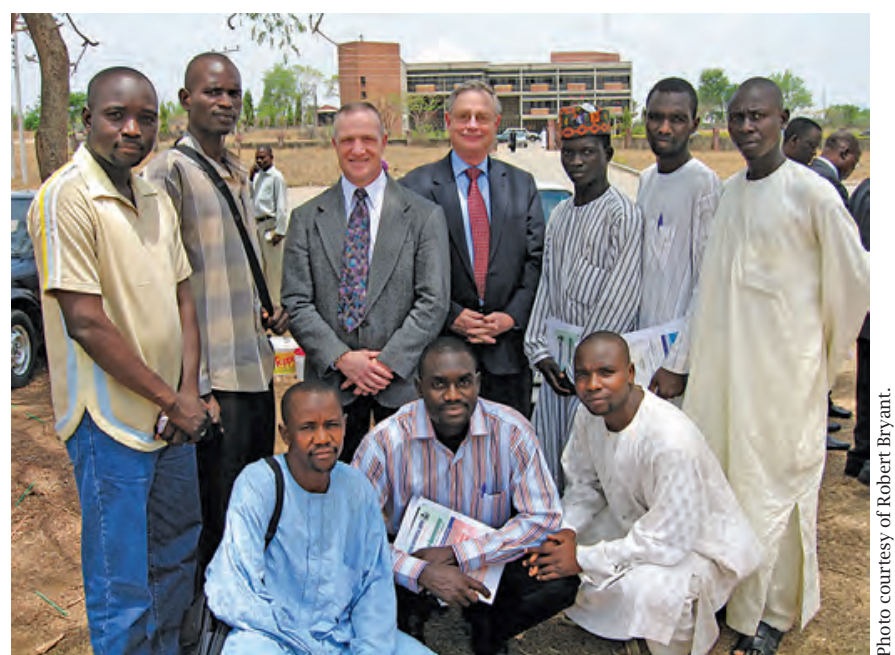

In March 2008, Robert Bryant (standing, third from left) visited the Nigerian Mathematics Center with Phillip Griffiths (center).

already. I'd placed out of a lot of classes, including the entire calculus sequence, plus the first chemistry and physics classes, so I graduated in three years by taking an overload every semester. Dr. Koh took my unusual background into account and gave me a lot of good advice about what courses to take.

When it came time to finish my bachelor's degree in math, Dr. Koh said, "Of course you will go to graduate school." I said okay, not really knowing what graduate school was, though some people had told me that the best place to go for mathematics was Harvard. Dr. Koh was convinced I'd get into Harvard, and so I didn't apply anywhere else (partly because I didn't want to "waste" my money on the graduate application fees). Well, I didn't get into Harvard. When I went to Dr. Koh's office to tell him this, he was shocked. "Well, where else did you apply?" he asked. I told him I hadn't applied anywhere else. I said, "I guess I'll go home and farm." He said, "You are not going to go home and farm!" So he took me that week, or maybe even the very next day, over to UNC. It was March, and all the applications to graduate school had been read, the offers made, and all of the financial aid had been given out. But he begged them to take me as a graduate student. And they did, just on his personal recommendation. I hadn't even taken the GRE, because Harvard did not require it (again, a cost-saving measure on my part).

Kids from families that are not tied into how higher education works still run into these kinds of problems. One thing I think is great about the Math Alliance ${ }^{1}$ is that it not only reaches out to underrepresented minorities but also to first-generation-to-college kids who are in the kind of situation I was. Without such programs, a lot of talent would be missed. So I'm glad the AMS is involved

\footnotetext{
${ }^{1}$ The Math Alliance is a national organization whose goal is to ensure that underrepresented or underserved American students having the talent and the ambition to earn a doctoral degree in the mathematical sciences have the opportunity to do so. See matha11iance.org.
} 
in supporting the Math Alliance.

When I started gradmathematician who had the most influence on me is Élie Cartan. uate school, I thought I would do analytic number theory. I like number theory a lot. But shortly after I arrived, I met the professor who would be my thesis adviser, Robert Gardner. He was a student of S.-S. Chern, so I am a "mathematical grandchild" of Chern. I had an excellent first-year course in differential geometry from Pat Eberlein, but under Robby Gardner I began to study Chern's work on minimal manifolds and minimal surfaces, and that's what really drew me into geometry.

Notices: Does number theory still have a place in your heart?

Bryant: Oh, yes. I've taught it only a few times, though. It's a beautiful subject, and I have a lot of fun with it, though I certainly wouldn't flatter myself that I could do research in it. To get to the forefront of an area, you have to have learned a lot about it and about the shape of the research boundary.

\section{Mathematical Heroes}

\section{Notices: Who are your mathematical heroes?}

Bryant: One is S.-S. Chern, of course. He had a huge influence on me. After I finished my thesis, he took an interest in it and in me, but, then, he was always encouraging to an enormous cohort of young people.

In my next to last year in graduate school (1978), Robby Gardner took me along with him to Berkeley, where he spent a sabbatical semester. It was my first time to California, and the first time I had spent any significant time outside of North Carolina. That was where I met Chern.

Chern shared his insights into the work of Élie Cartan, which Robby had introduced me to. The mathematician who absolutely has had the most influence on me is Cartan, though of course I never met him. But through Chern, who was Cartan's postdoc, I had a lot of exposure to Cartan's ideas in geometry and differential equations. I read a lot of Cartan's works-in fact, by now I have read all of them. A lot of the things he found interesting I find interesting too, and the work of his students was also attractive to me.

When I finished my degree, I got an NSF [National Science Foundation] postdoc and was at the Institute for Advanced Study during 1979-80, with Jack Milnor as my mentor. That was a special year in differential geometry at the IAS. S.-T. Yau, Rick Schoen, Karen Uhlenbeck, Leon Simon, Eugenio Calabi, and Jean-Pierre Bourguignon were all there, so it was a fantastic experience for a fresh $\mathrm{PhD}$ in geometry.

The other person who profoundly influenced me is Phillip Griffiths. Phillip's first job was at Berkeley, where he met Chern, and in this way he too was influenced by Cartan's viewpoint. Chern introduced the two of us in
1979, and Phillip and I started to work and publish together almost immediately after we met. It has been an incredible privilege to work with him. I've written more papers with Phillip than with anyone else. I have been very much influenced by his way of seeing all kinds of things from a geometric viewpoint.

I got my first tenure-track job in 1979 at Rice University, which was a wonderful environment. Reese Harvey was there, working on minimal manifolds, differential geometry, and the relationship between geometry and differential equations; he had a big influence on me. Through studying the work he did on calibrations with another great geometer, Blaine Lawson, I got interested in Riemannian holonomy, which has strongly influenced a lot of my later work.

\section{Reading Élie Cartan}

Notices: Is it true that Cartan's work is rather hard to read? That his notation is very difficult?

Bryant: His notation is a little different, but that's not where the difficulty lies. It's also not the French; his French is elegant, clear, and precise, though it can be hard to translate. (I was lucky that I had taken a couple of years of high school French and then another couple of French courses in college, so the language wasn't a barrier for me.)

What is very different about Cartan's work is that it is written in a style of mathematics uninfluenced by set theory. There is no "set notation" in Cartan's writing and very few formal definitions. He seemed to think of objects as being "subject to" rules rather than being "defined by" them. Instead of saying "Consider a map" or "Consider a domain," he would say, "Consider a point depending on some parameters." He almost never defined anything as a set, including domains and ranges for functions! He would talk about "primary variables" and "auxiliary variables" instead of the base and fiber of a fiber bundle. He doesn't give what we would consider to be a formal definition of differential forms. He describes the rules for calculating with them and how he thought about them-it's an almost physical sense of particles moving and interacting. Today we expect Bourbaki-ish presentations, with definitionexample-proposition-theorem. You don't see that very much in Cartan. He was also not wedded to expressing things in formulae when he could just explain how he was thinking. He has some short papers with no displayed equations at all. When we read Cartan, we are looking back into a time before set theory took over and getting a glimpse of how ninteenth-century mathematicians thought.

Cartan was very much a nineteenth-century mathematician in that sense, and he expected you to be able to do "routine" calculations on your own. Robby Gardner said he once was reading a paper by Cartan that said, "After a calculation that is long but not difficult..." and then gave a page of formulas. Robby worked out the calculations, and they took him more than thirty pages! Cartan was not being mean in doing this. He just felt he was telling you only the important things. 


\section{Mathematical Favorites}

Notices: Which of your mathematical results are you most fond of?

Bryant: If you asked others, they would probably say the proof of the existence of Riemannian manifolds with special holonomy, which was my first major result, in the early 1980s, and something that had been unresolved since Berger's original work on holonomy in the 1950s. It is a beautiful subject, and I had a lot of fun with it. It was certainly a high point in my career.

My interest in holonomy groups came out of a question raised in talks with Reese Harvey. He and Blaine Lawson had developed the theory of calibrations - a different calibration theory for each holonomy in Riemannian geometry. When Berger classified holonomy groups in the 1950s, there were two that were conjectured but not known to exist. I was intrigued, because this was exactly the kind of problem that the machinery of overdetermined systems of PDEs could handle. I had spent a lot of time learning Cartan's approach to exactly this sort of problem, so I could figure it out. That was my one paper in the Annals. It's a combination of beautiful exceptional geometry, Riemannian geometry, and PDEs.

I worked on it purely out of curiosity, and I learned a lot about Lie groups and other things in the course of the project, so I really liked it. But I didn't think more than a handful of people would be interested, so I was floored when I started getting letters from physicists about it. It turned out that these things are connected to supersymmetry. String theory, M-theory, F-theory-these are theoretical models that might be involved in understanding fundamental particle physics. All the different string theories could be brought together in the subject of special holonomy manifolds and their related geometric structures, so lots of physicists and mathematicians got interested. A few years after I proved their local existence and analyzed their generality, Dominic Joyce proved the existence of compact examples in an amazing tour de force of geometric analysis. That stimulated general interest even further, and it seems to still be growing. We are now trying to assemble a working group to look at special holonomy and string theory. So that's bringing me back to thinking about special holonomy.

But other results that I think are beautiful are not so well known. I worked on exotic holonomy groups and found the first example known of an irreducible holonomy group that was not in Berger's list. That had all these beautiful connections with twistor theory, path geometry, and a whole lot of other things. I've always been really fond of that paper from 1988. It took me a whole summer to write it, and I learned more writing it than from any other paper I wrote on my own.

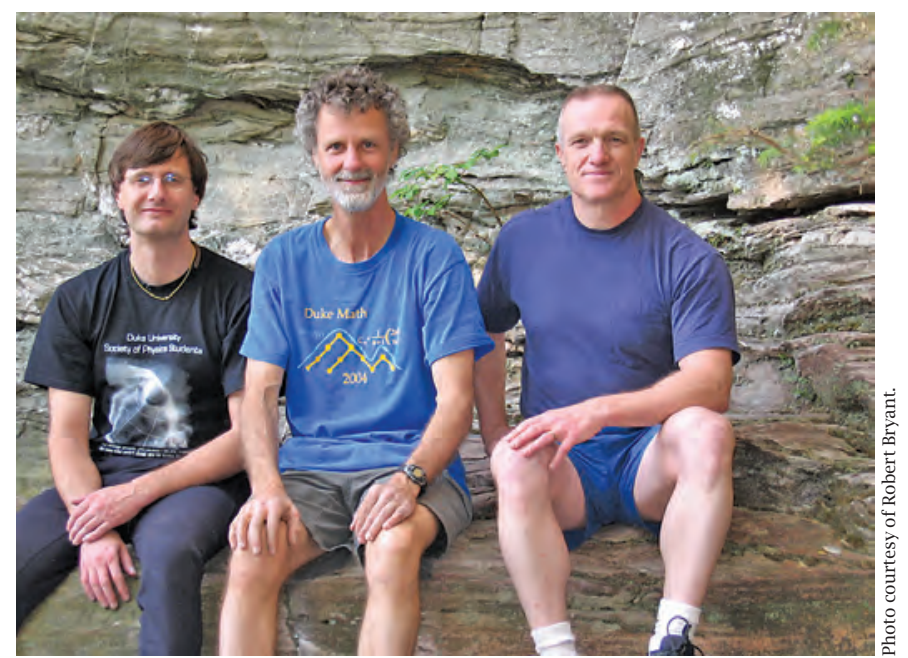

Bryant (right) and his colleagues Dick Hain (center) and Dan Gauthier take a photo break in a day of rock climbing in 2006.

There are a number of other bright spots. I have really enjoyed collaborating with Phillip Griffiths on the geometry of conservation laws for PDEs. That has been a lot of fun and remains an area of continuing interest for me.

Notices: What mathematical result do you look at and say, "That's great, but how did they do it? I never would have thought of it"?

Bryant: Oh yes, for me there are lots of those, too many to list. I remember when Terry Tao and Ben Green did their work on arithmetic progressions of primes, I was really intrigued. (Fermat's Last Theorem was a great breakthrough, too, but you have to be a number theorist to understand the technical details.) The work by Tao and Green was really new and imaginative, and the ideas could be explained without a lot of technical details. I delved into the proof, and it was full of things like that, where I would say, "I would never think of that!" But then, this was work by brilliant people. Maybe it's not so surprising that you would wonder how you could ever think of those things!

Even in differential geometry (my area), there are so many papers with startling results that I wouldn't have time to make a representative list. I have the "How did they ever think of this?" reaction all the time. But it's part of what keeps our love of mathematics new, that we get these wonderful surprises and that we can reshape our own thinking to take them in. I always think of that great line that was in the "About" box for HyperCard: "A day of acquaintance and then the longer span of custom, but first-the hour of astonishment." That's the way I feel about mathematics.

\section{The Math Community, Then and Now}

Notices: What changes have you seen in the mathematical community since you finished your PhD more than thirtyfive years ago in 1979 ?

Bryant: The mathematical community does look different to me now from when I was a postdoc, but then my vantage point is so different. One thing is that the 


\section{Stay as broad as you can while you find out what you are really passionate about.}

community seems a lot larger. My impression is that a lot more is published now. When I was a graduate student and Quillen solved the Serre conjecture, how did it get transmitted? Paper copies got passed around, and people organized seminars about the work. At each school people would at-

tend the seminar, talk about the paper, stop each other in the hallway later and chat, and say, "I just realized this...." There was more of that then. It felt more intimate. Now, so much new material appears every day on the arXiv that people feel overwhelmed. You and one other person in the department might study a paper, but there don't seem to be working seminars as we used to have, with concentration on a single subject or result. Also, it seems we have become more narrow. There are more people covering the ground, so each person covers a smaller piece of ground.

There are now 1,500 PhDs a year in the US, and a smaller percentage go into or stay in academia. Graduate students have more job opportunities outside academia, and the number of tenure-track jobs has not kept pace with the number of PhDs. When we were young, we thought doing research in mathematics was the ultimate goal. That's not so much the thinking today. There is more awareness of the connection of mathematics to other things.

Notices: What advice would you give young people coming into mathematics today?

Bryant: You want to stay as broad as you can while you find out what you are really passionate about. It is hard to develop the skill and knowledge to know what's possible and what makes sense to tackle. But it's got to be something you are passionate about, something you will sit up nights thinking about. That's what will sustain you

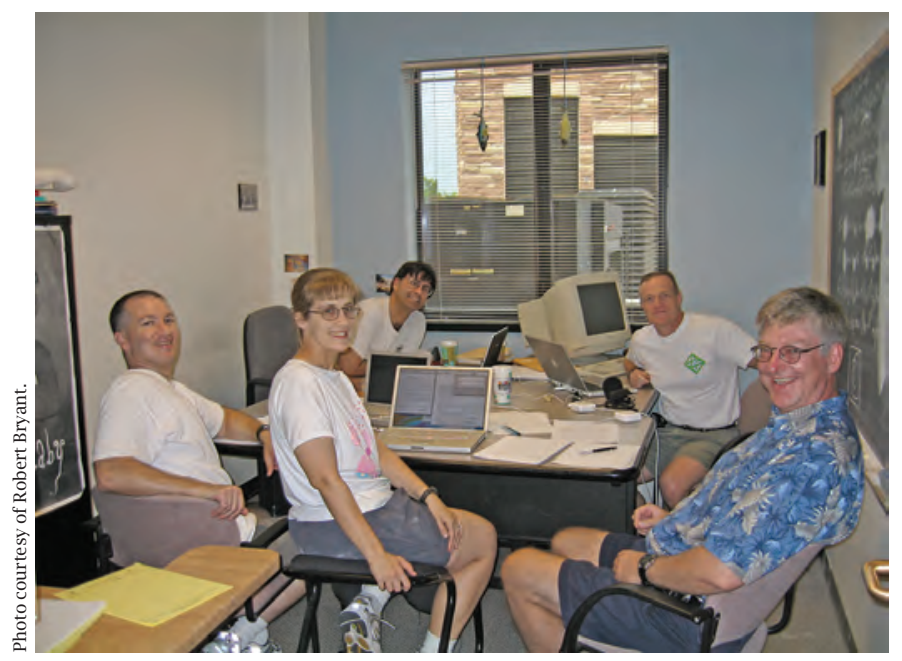

Bryant (second from right) in a working session with his former students Chris Moseley, Jeanne Clelland, and Thomas Ivey, as well as Bryant's colleague George Wilkens of the University of Hawaii. if, as with many people these days, you go through what is a pretty trying period with maybe two or even three postdocs before getting a tenure-track job.

It's hard not to get distracted because we are interested in so many different problems! But you need to be able to convince people you can see a problem through and that you understand it intimately. That's what people look for in accomplishment in mathematics. You have to have the stamina for that.

I think we are more collaborative than we used to be, which is a good thing. Working with others is wonderful. I've done a lot of collaborative work, and I think this is the way of the future, partly because we can communicate so much better. Remember, it used to be a big deal to place a long-distance phone call!

I also tell young people, you should get involved in your professional society. That might sound self-serving, since I'm president of the AMS! But it is important to stay connected, and the AMS gives people a way to do so. This is especially important for young people who are moving around a lot.

Notices: Can you say something about your personal life and how it has interacted with your professional life?

Bryant: Sure. They've been closely intertwined ever since I became a professional mathematician. I suppose one of the main ways my life has not been typical, though, is that I'm gay, which began noticeably interacting with my professional life when I met my partner (and now husband), Réymundo Garcia, within a week of moving to Houston in 1980 to start my position at Rice. Up until that time I had kept my personal life separate from my professional life (as was common for gay men then), but after meeting Réy and joining the department at Rice, that separation quickly faded away. Although Texas, like most southern states at that time, criminalized gay men, we found the environment at Rice and in the department to be very welcoming. In fact, I'm pleased to be able to say that we have found the mathematics community in general and my colleagues in particular to be fully welcoming and supportive throughout my career.

That said, I'm aware that not everyone has had the same positive experience we have, and even when our environment was personally welcoming, we faced some challenges. As many other LGBT [Lesbian, Gay, Bisexual, Transgender] folks have found, the lack of official recognition of their personal relationships can cause real difficulties. So, when we moved to Duke in the late 1980s, we started working on getting Duke to recognize same-sex domestic partners and grant benefits equivalent to those for married couples. It took a fair amount of community organizing and meetings with the administration, but eventually, when, in 1995, Duke started providing samesex domestic partner benefits (the first university in the South to do so), Réy and I were the first couple to sign up.

Another thing that made me really proud of our mathematics community, and the AMS and the MAA [Mathematical Association of America] in particular, came when Colorado passed Amendment 2 in 1992, a regressive measure that essentially outlawed ordinances that would protect LGBT people against discrimination. In 


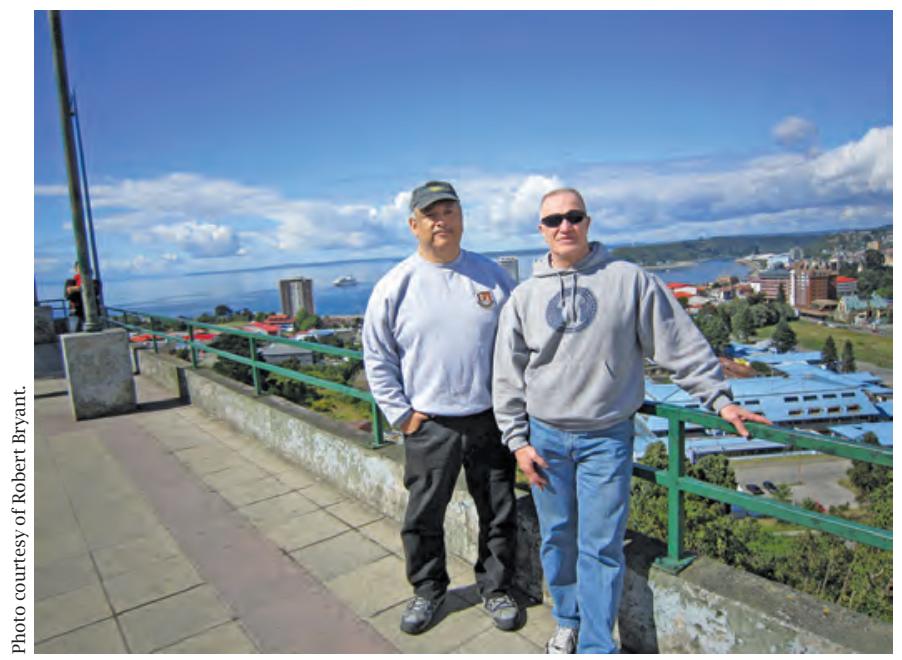

Robert (right) and Réy visiting Puerto Montt, Chile, in 2014.

response, the AMS and MAA voted to move the 1995 Joint Mathematics Meetings from Denver, where it had been scheduled to be held, to San Francisco. That show of support and concern was literally an inspiration for a group of us to put together the first reception for LGBT attendees at the Joint Meetings in San Francisco. Now, twenty-one years later, the tradition of this reception is still going on. The social events and networking at the JMM are often accompanied by fora and sessions in which we talk about how to deal with nonsupportive environments for LGBT folk. These events supply valuable information and support, particularly to young people who are just starting their professional careers in mathematics and are

\section{The mathematics} unsure how welcoming the community is.

\section{community has been fully welcoming and supportive.}

While things have improved dramatically in the past thirty-five years, we ought to keep in mind that it's still a big step for many people with nontraditional identities to be open about their personal lives in a professional setting. That's one reason it's so important that the AMS and MAA have statements reminding us all to continue to think about how we can provide supportive, safe, and welcoming environments for the increasingly diverse world of mathematicians of all kinds.

It's seeing how our mathematical organizations have been a force for good in these and many other ways that has made me glad and proud to serve in the various roles I've had in the AMS and MAA. I'm very grateful for the kindness and trust that my colleagues have placed in me in asking me to serve and for the amazing generosity that so many have shown, giving their time and talents to serve our community.

\section{Epilogue}

In the months since this interview took place, a number of states, including North Carolina, have taken up or passed legislation of a similar discriminatory nature to Colorado's Amendment 2. President Bryant deplores these developments and is proud to call attention to and to support the AMS' continuing policy of maintaining an environment that encourages, welcomes, and includes diversity in all of its meetings and functions.

\title{
Twenty Years Ago in the Notices
}

\section{June/July 1996}

\author{
Mathematics: A Century Ago- \\ A Century from Now \\ by John Ewing.
}

The mathematics profession in the United States was quite different one hundred years ago-or was it?

www. ams.org/notices/ 199606/ewing.pdf 